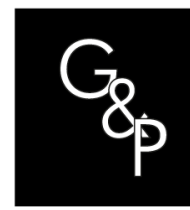

\title{
Reference model for building innovation networks in information technology
}

\author{
Modelo de referência para a formação de redes de inovação em \\ tecnologia da informação \\ Adauto Lucas da Silva ${ }^{1}\left[\right.$, Fábio Müller Guerrini ${ }^{1}[$ ] \\ ${ }^{1}$ Universidade de São Paulo (USP), Escola de Engenharia de São Carlos (EESC), São Carlos, SP, Brasil. E-mail: \\ adauto_Is@yahoo.com.br; guerrini@sc.usp.br
}

How to cite: Silva, A. L., \& Guerrini, F. M. (2021). Reference model for building innovation networks in information technology. Gestão \& Produção, 28(3), e4651. https://doi.org/10.1590/1806-96492021v28e4651

\begin{abstract}
The change in organizational processes by means of associating the new resources made available by IT (Information Technology) with the intrinsic characteristics of business-related areas embodies one of the innovation concepts. This work proposes a reference model for the formation of innovation networks focused on implementing systems that represent innovations by associating IT with the business area. The research methodology is based on an exploratory case study, composed of several analysis units, and on the organizational modeling methodology EKD (Enterprise Knowledge Development) to formulate the reference model. This research proposition contributes to systematize the formation process of collaborative alliances among the innovation agents in order to implement Information Technology-based systems.
\end{abstract}

Keywords: Innovation; Reference model; Innovation networks; EKD; Information technology.

Resumo: A mudança nos processos organizacionais por meio da associação dos novos recursos disponibilizados pela $\mathrm{TI}$ (Tecnologia da Informação) com as características intrínsecas das áreas relacionadas aos negócios materializa um dos conceitos de inovação. Este trabalho propõe um modelo de referência para a formação de redes de inovação com foco na implementação de sistemas que representem inovações por meio da associação da TI com a área de negócios. A metodologia de pesquisa é baseada em um estudo de caso exploratório, composto por diversas unidades de análise, e na metodologia de modelagem organizacional EKD (Enterprise Knowledge Development) para formulação do modelo de referência. Esta proposta de pesquisa contribui para sistematizar o processo de formação de alianças colaborativas entre os agentes de inovação para a implantação de sistemas baseados em Tecnologia da Informação.

Palavras-chave: Inovação; Modelo de referência; Redes de inovação; EKD; Tecnologia da informação.

\section{Introdution}

According to Organização para Cooperação Econômica e Desenvolvimento (2006) the innovation carried out by companies is given in the form of new products, new production methods and transport, new forms of industrial organizations, and by creating new markets.

Received: Nov. 26, 2019 - Accepted: Jul. 28, 2020

Financial support: None.

This is an Open Access article distributed under the terms of the Creative Commons Attribution License, which permits

unrestricted use, distribution, and reproduction in any medium, provided the original work is properly cited. 
Hallikas et al. (2009) suggest that innovation depends on the companies' ability to create, recognize, retain, transmit and use the knowledge available from the multiple and diverse funding sources available (Chesbrough \& Prencipe, 2008; Palmberg, 2006; Faems et al., 2005).

Innovation is a process that involves the interaction of different actors (Najafi-Tavani et al., 2018; Hausman, 2005; Prajogo \& Ahmed, 2006; Zeng et al., 2010; Freel \& Harrison, 2006). According to Silva and Guerrini (2018), Rycroft \& Kash (2004), and Tsai (2009), the innovation networks have emerged as a response to the increasing technology complexity in products and processes, due to the need for a faster market response, the multidisciplinary nature of new technologies and the need to mitigate costs and risks. The ability to join innovation networks is a viable way to meet the new market challenges, through which organizational barriers can be overcome in order to achieve the common goals by the partners involved.

According to Swafford et al. (2008), Bartel et al. (2007), Ryssel et al. (2004), IT investments can represent important innovations for any company faced with competition. However, Zeraati \& Rajabion (2020), Kwak \& Stoddard (2004), Legris et al. (2003), AlAhmad et al. (2009), Andersson et al. (2008), Higuera \& Haimes (1996) call attention to some of the elements that contribute to failure in implementing IT-based systems, such as the complexity of business processes, the lack of project changes, the setting up of immediate objectives, the lack of knowledge shown by consultants regarding the customer's business, and technological heterogeneity. Some of the consequences that emerge from this scenario are the automatization of inefficient processes, waste of time and financial resources, misalignment with organizational goals and low compliance systems in relation to business (Carvalho \& Guerrini, 2017).

As the fierce competition among companies underscores the importance of fully understanding the success factors that are behind innovation in products and processes (Jesús Nieto \& Santamaría, 2007; Weichhart et al., 2018), we have the following research question: How can innovation networks be formed to enable Information Technology projects that represent innovations by the association of IT and business-related areas?

In order to answer that question we propose a reference model to support the building of innovation networks. According to Camarinha-Matos \& Afsarmanesh (2008), a reference model is an abstract representation of an environment, system or entity in the physical, social, or logical level, which allows knowledge to be represented for the overall understanding by those involved with each analysis object by means of structuring a web of concepts, roles and definitions (Plisson et al., 2007).

The reference model is represented by Enterprise Knowledge Development (EKD) methodology, further six interactive submodels: goals, business rules, business processes, actors and resources, concepts.

\section{Theoretical framework}

Companies seek to answer the uncertainties and opportunities of their turbulent environments (Armoutis et al., 2008; Katzy \& Crowston, 2008). According to Chen \& Tsou (2007), Patrakosol \& Olson (2007), Prajogo \& Ahmed (2006), innovation is an alternative to maintain sustainable competitiveness within the scenario of growing demand for quality, price and customer service.

Amara \& Landry (2005), Andersson et al. (2008) and Jesús Nieto \& Santamaría (2007) argue that innovation effort is constrained by factors such as the complexity of the processes and technology, the need for knowledge, competition, availability of financial resources and human capacity. According to Freel \& Harrison (2006), lyer et al. (2006) and Becker \& Dietz (2004), innovation networks have effectively supported innovative 
projects through well-defined, structured partnerships in order to meet the common goals, hence improving quality, reducing costs and market time response.

\subsection{Innovation networks}

According to Camarinha-Matos \& Afsarmanesh (2005), innovation networks are entities formed by several independent, geographically distributed institutions that are heterogeneous in culture, environment, social capital and goals, and that work together to achieve common or compatible goals. To Freel \& Harrison (2006), innovation networks are a set of institutions linked by collaborative ties in order to overcome, in partnership, the uncertainty of innovation processes, participating in the generation, marketing and distribution of products, and also in the improvement of processes and services.

The search for expanded skills within the companies has forced establishing collaborative alliances in order to share know-how, human capital, technology, infrastructure and financial resources (Sari et al., 2007; Emden et al., 2006). According to Lee et al. (2007), Tsai (2009) and Soriano \& Urbano (2009), collaboration between companies or within the same organization, is a powerful way to stimulate the creation of new ideas and, consequently, to develop innovations.

The advances in IT have been greatly responsible for the viability of this kind of network, because they change the organizational focus on data manipulation to the processing of information and to the production of knowledge, as suggested by Camarinha-Matos \& Afsarmanesh (2008).

\subsection{Information technology as an innovation element}

Bharadwaj et al. (2007) state that the complexity of technologies, business processes, organizational systems, and the need to get rid of inconsistent information requires a continuous and well structured interaction between IT and the business areas.

To improve operational business-IT alignment, the development of IT-based systems can be derived from business requirements (Bagheri et al., 2019).

This complexity is corroborated by the fact that despite all the investment made in the implementation of IT-based systems, the success rates are still relatively low (Legris et al., 2003; Al-Ahmad et al., 2009). According to Kwak \& Stoddard (2004), during project implementation, the agent's tendency is to focus on short-term goals and as the project grows in size and complexity, the corresponding management effort increases exponentially (Higuera \& Haimes, 1996).

Yi et al. (2006) points out that setting realistic goals makes easier the commitment of those involved in a collaborative process. Andersson et al. (2008) state that the technicality of vendors and the heterogeneity of IT are great barriers to be overcome. Grover et al. (1998) believe that all software implementation must be accompanied by a change in project, because the acquired benefits result from the organization's own efforts to achieve the desired goals (Ettlie et al., 2005).

Mohamed et al. (2006) and Ettlie et al. (2005) argue that the use of state of the art technology is not enough to ensure the success of an innovating process, because it is only by aligning technology with the organization's goals that technology can be fully exploited.

According to Hsu (2005), due to the heterogeneity and complexity of systems, a company rarely has all the necessary knowledge to innovate. Another problem observed by Andersson et al. (2008) regards the fact that software should be built on different technology platforms and be offered by a wide range of suppliers so that it does not 
become a barrier to its successful implementation. Thus, innovation through the implementation of IT-based systems is the result of a collaborative process that requires sharing knowledge and experiences.

A reference model can improve the requirements elicitation process and contribute to the creation of a common understanding between business and IT alignment (Bagheri et al., 2019).

To develop a reference model the next section will present the Enterprise Knowledge Development (EKD) methodology. The process modelling using EKD provides the capture of organizational requirements in six different organization perspectives.

\subsection{EKD (Enterprise Knowledge Development) as modelling methodology for knowledge management}

According to Bubenko et al. (2001), a model is a structured form that represents the knowledge of a company in order to improve the understanding of internal and external contexts, simplifying the communication between the agents involved. To Kirikova (2000), a model needs to combine the element of representing knowledge within its structure with the ability to transmit this knowledge to the public. Nurcan and Rolland (2003) claim that the EKD methodology provides a method for developing and documenting organizational knowledge and helps companies to develop models in order to manage changes.

According to Bubenko et al. (2001), EKD output is a set of conceptual and interrelated models to provide a multifaceted view of a company. The Goal Model describes the company's essential goals, while elucidating the reasons for the components of other models. The Business Rule Model is used to set and maintain explicit rules and policies that guide the behavior of the company within the business context. The Business Process Model maps the physical (material) and logical (information) flow. The relationship of this model with the others justifies the presence of each business process mapped. The focus of the Actors and Resources Model is on the organizational structure, in other words, on the agents/individuals, units, roles and resources. The Concept Model is used to define the terms and concepts mentioned in the other models, elucidating the understanding of the knowledge recorded in each sub-model of the EKD. The Technical Components and Requirements Model combines the technical requirements for developing and implementing a system. The EKD also provides guidelines to indicate the appropriate activities, under certain conditions, intended for organizational change. The Figure 1 presents the EKD methodology.

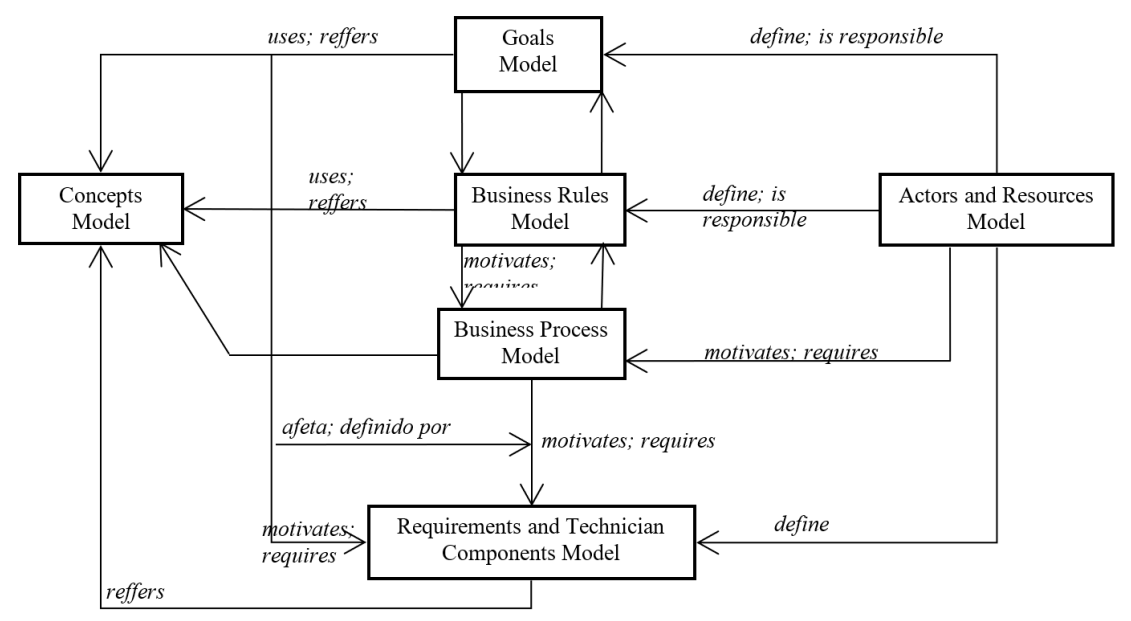

Figure 1. EKD methodology. Source: Bubenko et al. (2001). 


\section{Research Method}

According to Yin (2005), the case study methodology is to assess the phenomena embedded in a social context, in which the researcher has little or no control, by evaluating questions such as "How" and "Why." The objective of this research is the formation of innovation networks to implement Information Technology-based systems. As the formation of collaborative networks, as a business strategy, cannot be dissociated from its organizational context, the case study, as a research methodology, will enable to investigate the circumstances that contribute to the organized formation of these networks.

Yin (2005) suggests that the construct validity can be evidenced by the search for convergence among the various sources of information that comprise a scientific research. In this study the literature review, the evaluation of the case study (supported by the questionnaire generated from the literature review) and the modeling methodology, provide multiple perspectives to assess the study object, whose convergence supports the construct validity.

Regarding the external validity, it can be seen that all the units of analysis studied represent automation projects for common organizational processes by implementing Information Technology-based systems.

According to Yin (2005), a research protocol can increase the reliability of a survey because it provides the standard procedures followed by the researcher and which can be repeated by other researchers. The protocol of the case study presented in Table 1 shows an overview of the research, stating that this is an exploratory research intended to help disseminate the analytical concepts of innovation networks.

Table 1 shows the case study protocol.

Table 1: Case study protocol.

\begin{tabular}{|c|c|}
\hline Type of research & Exploratory. \\
\hline Study Question & How can Information Technology innovation networks be formed? \\
\hline Analysis Units & Projects to implement Information Technology-based systems. \\
\hline Time Unit & From 2009 to 2010. \\
\hline Place & Multinational company in the chemical sector. \\
\hline Construct Validity & $\begin{array}{l}\text { The convergence of the literature review, case study, questionnaire, and } \\
\text { modeling methodology provides a variety of perspectives to assess the } \\
\text { study object. }\end{array}$ \\
\hline $\begin{array}{l}\text { External validity (Domain } \\
\text { in which the findings can } \\
\text { be generalized) }\end{array}$ & $\begin{array}{c}\text { As all units of analysis represent automation of organizational } \\
\text { conventional projects by implementing Information Technology-based } \\
\text { systems, an analytical generalization of other similar-size companies } \\
\text { can be considered, taking as basis the replication of the results } \\
\text { presented by the case study. }\end{array}$ \\
\hline Reliability & Use of a case study protocol. \\
\hline
\end{tabular}

Figure 2 shows the conceptual model on which the research is structured. Among the many definitions of the innovation concept, the concept formulated by the Oslo Manual (Organização para Cooperação Econômica e Desenvolvimento, 2006) was chosen.

As outlined in Figure 2, the innovation research can be verified by the case study and is associated with the change in the processes by implementing Information Technology-based systems. The theoretical framework on innovation networks and the case study support the proposition of the reference model. The theoretical framework on innovation, the EKD reference model and the concept that the cooperative links contribute to the transfer of innovation, come together to motivate the formation and the structure of innovation. 


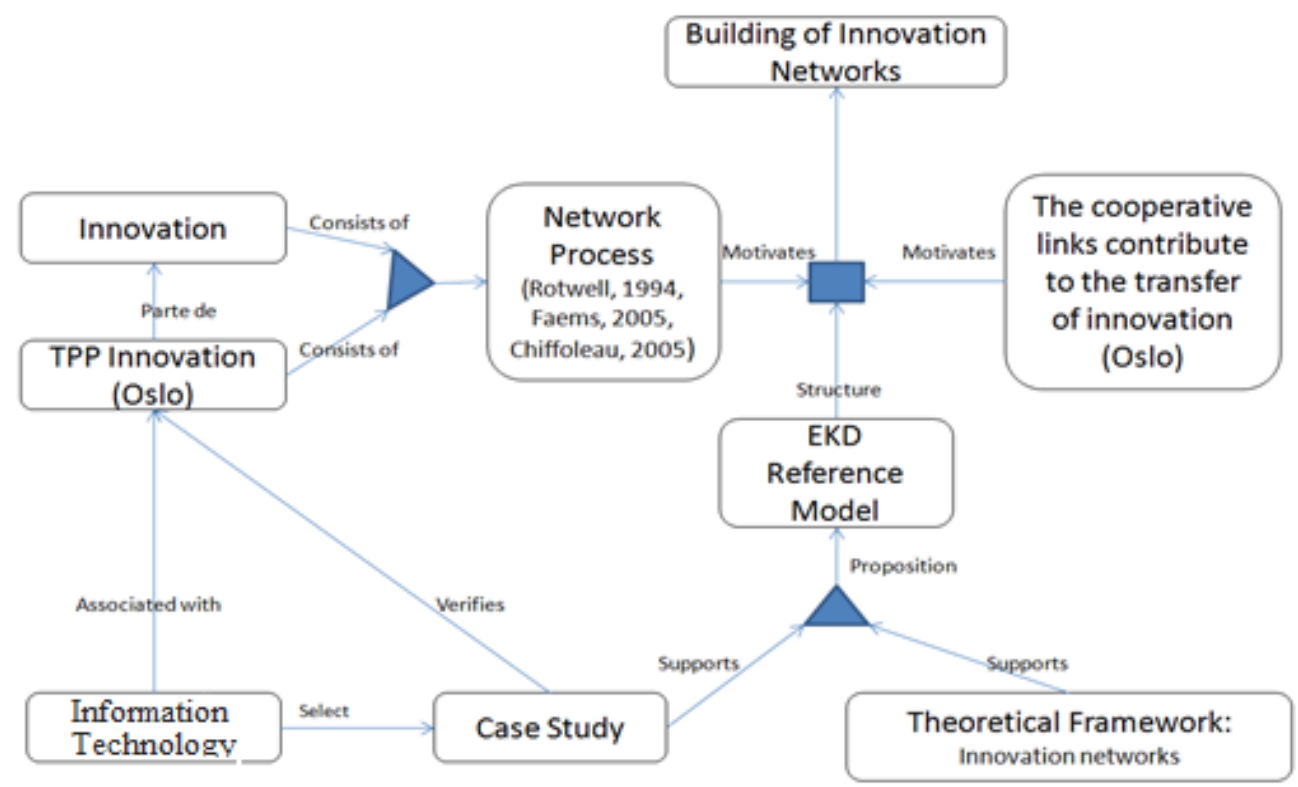

Figure 2. Concept model of the research.

\section{Data collection and analysis}

The company, which is the object of this research, is the main subsidiary of a German group with about 2,700 employees distributed throughout two production units in São Carlos, state of São Paulo, Brazil. Inserted in the chemical industry, this company focuses on the production of educational material and cosmetics. This company was chosen because the interdependence between internal business units turns them into a repository of agents able to integrate the structure of the innovation network proposed in this paper.

The units of analysis were selected in line with the strategic importance to the company, according to the complexity and importance related to business, and in some cases projects whose software complements the functionality of ERP (Enterprise Resource Planning).

An analysis of each individual case to implement Information Technology-based systems was carried out, totaling seven units of analysis (Table 2):

Table 2. Description of the units of analysis.

\begin{tabular}{|c|c|}
\hline Unit of analysis & Description and year of implementation. \\
\hline $\begin{array}{l}\text { 1. Manufacturing } \\
\text { Execution } \\
\text { System (MES). }\end{array}$ & $\begin{array}{c}\text { The MES collects data of the factory floor and integrates them to the ERP, } \\
\text { enabling managers to give faster response to the problems. The project had the } \\
\text { support of a consultant, a general manufacturing coordinator, an electric } \\
\text { engineer, and an IT infrastructure analyst. Year: } 2010 \text {. }\end{array}$ \\
\hline $\begin{array}{l}\text { 2. System for } \\
\text { managing events } \\
\text { generated by } \\
\text { consumers. }\end{array}$ & $\begin{array}{c}\text { The system receives consumer complaints by the customer service. The project } \\
\text { involved a team of consultants responsible for the software, an analyst for } \\
\text { customer relationship, a marketing coordinator and an analyst for IT } \\
\text { infrastructure. Year: } 2009 .\end{array}$ \\
\hline $\begin{array}{l}\text { 3. SAP/R3 } \\
\text { Module Plant } \\
\text { Maintenance } \\
\text { (PM). }\end{array}$ & $\begin{array}{c}\text { The maintenance management system schedules the maintenance activities, } \\
\text { management of worked hours and the inventory of parts and components. The } \\
\text { ERP module enables associating the demands with the needs imposed by the } \\
\text { natural wear of the machines. The project involved a team of consultants } \\
\text { specialized in ERP, a general coordinator of maintenance, and an IT } \\
\text { infrastructure analyst. Year: } 2009 .\end{array}$ \\
\hline
\end{tabular}


Table 2. Continued...

\begin{tabular}{|c|c|}
\hline Unit of analysis & Description and year of implementation. \\
\hline $\begin{array}{l}\text { 4. System to } \\
\text { support Sales } \\
\text { Force. }\end{array}$ & $\begin{array}{l}\text { The system collects the demand of orders in the sales area. The project } \\
\text { involved a team of software consultants, two IT analysts (one from the } \\
\text { infrastructure area and another from the process area), a business analyst from } \\
\text { the sales area and a business coordinator. Year: } 2010 .\end{array}$ \\
\hline $\begin{array}{l}\text { 5. System for } \\
\text { controlling the } \\
\text { specification of } \\
\text { products. }\end{array}$ & $\begin{array}{l}\text { The system gathers the information needed to develop a product. The } \\
\text { manufacturing area uses part of the information as guideline to execute the } \\
\text { tasks that include production and quality control. The project team consisted of } \\
\text { an external consultant, an internal coordinator (area requester), and an IT } \\
\text { infrastructure analyst. Year: } 2009 .\end{array}$ \\
\hline $\begin{array}{l}\text { 6. System for } \\
\text { managing quality } \\
\text { audits. }\end{array}$ & $\begin{array}{c}\text { The system stores the information of internal, external and third party audit processes. } \\
\text { It allows data entry and sharing the information. The project included an external team } \\
\text { of experts in quality standards, a coordinator of the internal quality area and an IT } \\
\text { business analyst. Year: } 2009 .\end{array}$ \\
\hline $\begin{array}{l}\text { 7. System for } \\
\text { assembling an } \\
\text { investment plan. }\end{array}$ & $\begin{array}{c}\text { The system allows managers to set budgets based on parameters previously } \\
\text { set in the system, which in turn originated from the strategic guidelines adopted } \\
\text { by the company board. The project had the participation of an expert consultant } \\
\text { in the software purchased, an internal expert in finance (requesting area), an IT } \\
\text { infrastructure analyst. Year: } 2010 \text {. }\end{array}$ \\
\hline
\end{tabular}

Initially, a pilot questionnaire was submitted to the coordinator of one of the units of analysis, which in addition to answering this first version, helped in the critical evaluation of issues in order to verify compliance with the context in which they would be applied. After this questionnaire was completed, it was submitted to each employee responsible for coordinating each unit of analysis.

The decision to interview the coordinator of each project (belonging to the business areas) brought about more reliable results to the research, due to the fact that they participated in key decisions. This criterion to select the respondents resulted in the selection of employees from different levels of the company. To facilitate understanding the goals of this study, each respondent received a brief training on the concepts used in this study as well as an explanation of the questions and an overview of the EKD methodology.

The questionnaire had the questions grouped into five major sections: innovation, formation of the innovation network, IT as element to support innovation, the need of a reference model for the formation of the innovation network, and the conceptual use of EKD models to detect the compliance of the project with the company as well as the maturity of the team for managing the goals, change and the knowledge produced.

The elaboration of the questionnaire derived from these themes followed the observations of Hair et al (.2007), who advocate that this type of question needs to be easily understood by the respondent, non-compromising and / or embarrassing, without inducing the respondent to a certain answer and without multiple interpretation. In addition to the questionnaire being supported by the theoretical framework, its preparation also had the help of the coordinator who was one of the project managers represented by the analysis unit number 1 .

Questions 1-4 of the questionnaire are related to the concept of innovation. The purpose of this block of questions is to find out if the deployment team was familiar with this concept, whether the project was targeting innovation, whether there was a favourable environment, and what the perception of project outcomes was.

Questions 5-8 of the questionnaire address the formation of the innovation network. The purpose of these questions is to verify the composition and structure of the network, to assess if there were supporting factors, and to identify the main criteria for integrating members into the network. 
Questions 9 to 12 of the questionnaire seek to verify if there was an approximation between IT and the business area, what are the benefits of this approach, what are the pre-established goals for the system and what are the main results verified after the implementation.

Questions 13 to 17 of the questionnaire seek to determine the need for a reference model for the formation of the innovation network. The intention is to evaluate the level of planning, the organization and execution of the software implementation project, verifying the study of the scenarios, the definition of the indicators, and the documentation of the generated knowledge.

Questionnaire questions 18 through 23 conceptually use the EKD models to detect the project's level of alignment with the company's macro objectives, the rules and constraints that support the achievement of these objectives, the level of coordination between team members and maturity in knowledge management.

Each section of the questionnaire received 20 points, therefore a total of 100 points. Each question received the number of points of their section divided by the number of issues in this group. We used a Likert scale to standardize the information collected in the field.

The section that addressed innovation had top score of $73 \%$ and a minimum score of $15 \%$. The section that evaluated the formation of the innovation network had top scores of $74 \%$ and a minimum of $24 \%$. The IT section had a maximum score of $85 \%$ and a minimum of $20 \%$. The section to assess the need for a reference model for the formation and operation of innovation networks had a maximum score of $65 \%$ and a minimum of $19 \%$. The section that used the EKD concepts to detect the level of alignment of each project with the macro objectives of the organization, the level of coordination of efforts and maturity in relation to knowledge management presented a maximum score of $64 \%$ and a minimum score of $25 \%$.

The reason for this poor performance was a set of factors recorded in the questionnaire responses such as the lack of basic knowledge about the innovation concepts and about the formation of networking innovation, the absence of a pre-established approach to implementing the systems, communication problems, resistance of the people / company to change, lack of management for process changes, lack of building scenarios to improve the planning of the impacts resulting from the change, lack of the definition of a script widely discussed, and lack of an adequate approximation of the areas involved (business, information technology and consulting).

Figure 3 shows that the performance of the group of analysis units in relation to the concepts of innovation, network formation and IT support for the business area are respectively $46 \%, 44 \%$ and $44 \%$. There is a contrast between these numbers and the intention to innovate expressed by project coordinators, and it helps understanding the low degree of change achieved. These percentages indicate that the teams did not dominate the concept of innovation and its requirements, very little was known about network theory and there was no opportunity for IT departments and business to more appropriately associate in order to evaluate the company's demands that could be achieved by the potential of new technological resources.

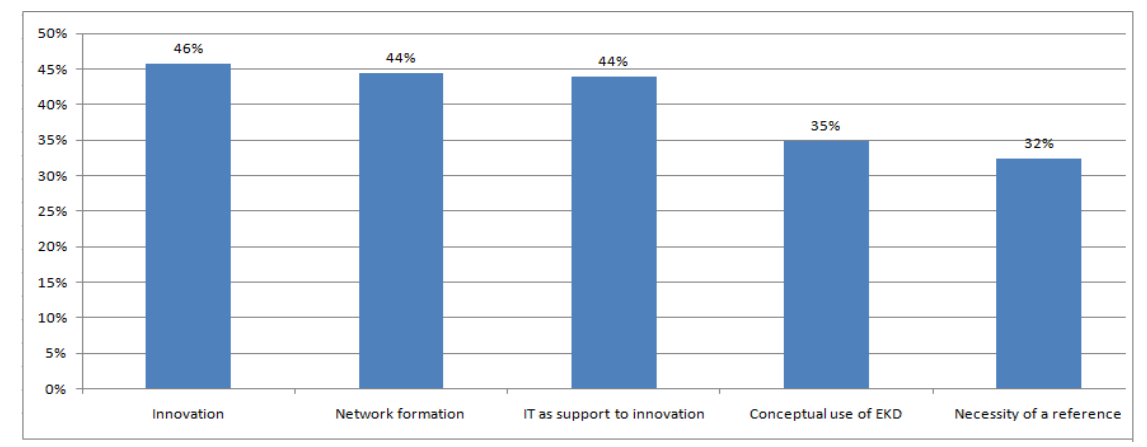

Figure 3. Overall performance by concept. 
The factors listed by the Organização para Cooperação Econômica e Desenvolvimento (2006) as detrimental to a company's ability to innovate coincide with some situations found in the research, such as the inability to articulate the inner potential of innovation, lack of qualified personnel, resistance to change in the company, the lack of knowledge related to technology advances and the market changes. The consultants took over an important part of the responsibilities. The demerit of this situation was the internal teams' lack of basic conceptual knowledge about innovation, networking and organizational modeling. This facts contradicts Cohen \& Levinthal (1990), for whom innovation requires the availability of previously accumulated internal knowledge.

Despite the overvaluation of individual experience in each project, only expertise was not enough, confirming Hausman (2005), Rycroft \& Kash (2004), Prajogo \& Ahmed (2006), Jesús Nieto \& Santamaría (2007) who maintain that innovation is increasingly less about the product of an isolated effort, requiring a more successful interaction between different actors (Zeng et al., 2010; Freel \& Harrison, 2006).

It was observed that an adequate disclosure of the objectives to be achieved was not in place. The same problem was repeated for the roles and responsibilities of the agents, as well as for the rules, policies and restrictions associated with the business. Soriano \& Urbano (2009) states that the confidence and commitment for network collaboration depends on the communication and the efforts to construct governance policies, network membership rules, clear definition of taxes and benefits. The data analysis reinforces the need for a reference model to organize these procedures and systematize the formation of innovation networks in information technology.

\section{Results}

Based on the Enterprise Knowledge Development Methodology (EKD), and on the analysis of the elements of IT-systems implementation among, and on the information's collected in the interviews and in the literature, was elaborated the reference model developing the goals Model, Business Rules Model, Business Processes model, Actors and Resources Model, and Concepts Model. The Technical Components and Requirements Model was not developed, keeping in mind that it is directed to the development of an information system, which is not part of the research scope.

\subsection{Goals Model}

To systematize the implementation of Information Technology-based systems in order to bring innovation to the business (Goal 1) requires supporting the concept of innovation (Concept 1). Goal 1 enables Opportunity 1 to respond more effectively and with more stability to the opportunities presented by the business market.

Goal 1.1 deals with the formation of the innovation network, bringing organization and assurance to the partners. Goal 1.2 proposes linking the software implementation to a change plan. Threat 2 , detected by the case study by the rigidity and inflexibility of the organizational culture, can restrict executing this goal. Goal 1.3 addresses the intersection between the potential of new technologies with the business characteristics. To compare these two elements it is necessary to operate the state of the art technology (Goal 1.3.1) to obtain the maximum 
functionality and tooling available. Goal 1.4 defines the intention of creating a culture of organizational knowledge management. Goal 1.5 seeks to combine the complementary skills necessary for the implementation of projects. Thus, external partnerships can be set up to address technical or methodological deficiencies (Goal 1.5.1). Goal 1.6 aims to break down barriers that prevent the processes of organizational change, and it needs the agents' commitment (Goal 1.6.1) and the support from top management (Rule 3).

Uniting all these goals provides a set of essential requirements for the IT-based systems to overcome the condition of a mere technical tool and start adding value to the business. Figure 4 shows the Goals Model.

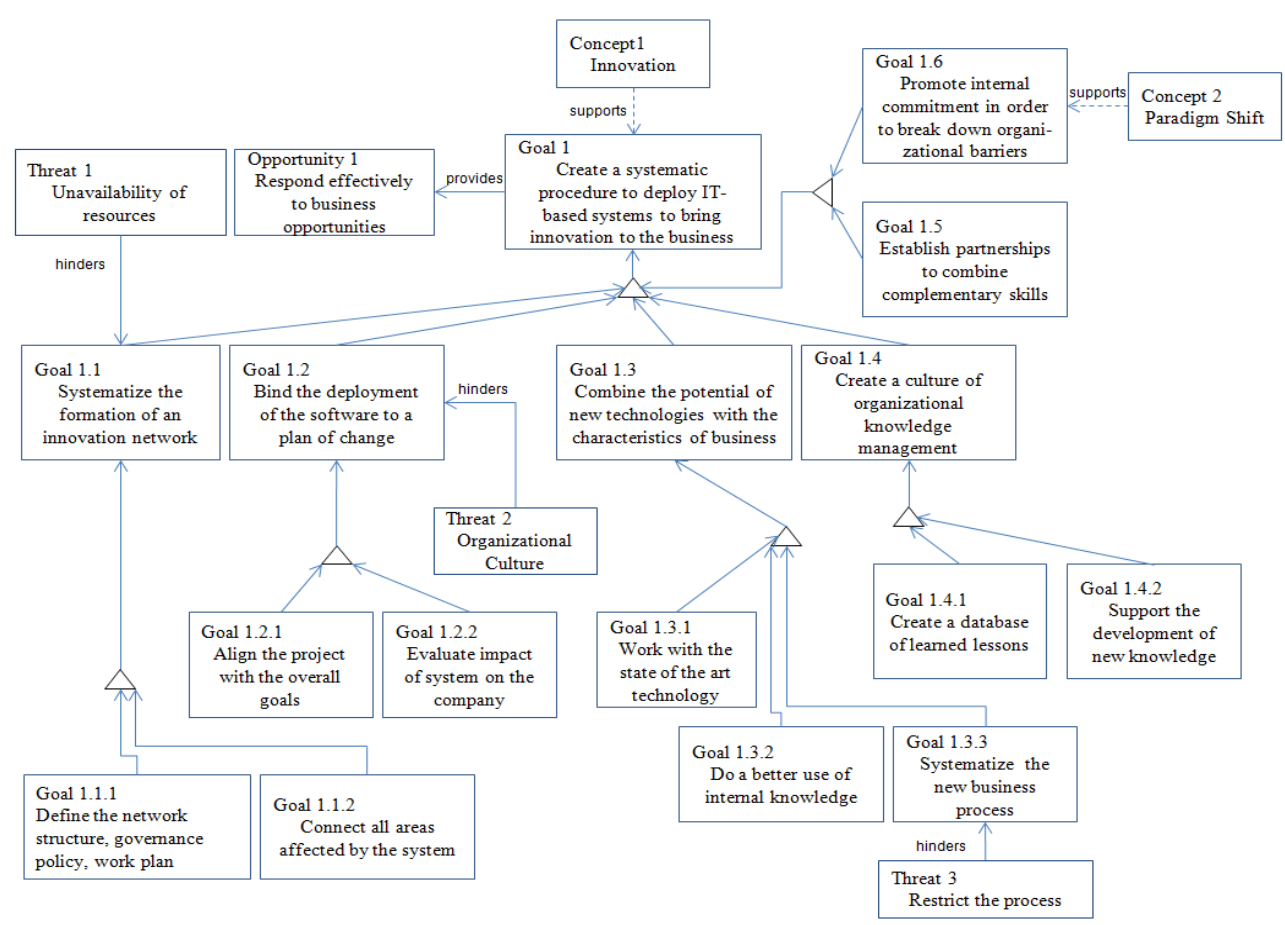

Figure 4: Goals Model of the research.

\subsection{Business rules model}

In order to systematize the implementation of IT-based systems to bring innovation to the business (Goal 1) it is essential that the deployment team knows the complexity of the business and the technology to be implemented (Rule 1). Hence the need to select an internal multidisciplinary team (Rule 2) to establish external partnerships (Goal 1.5.1) to combine complementary skills (Goal 1.5 and Rule 16). The initiative of this multidisciplinary team is to support the junction between the potential of new technologies with the business features (Goal 1.3), making use of the state of the art technology (Goal 1.3.1). Setting up a roadmap and the support of top management (Rules 3 and 5) support Goal 1.2, as any change means breaking down organizational barriers (Goal 1.6).

Rule 2 is supported by Rule 9 (the need to define criteria for the network formation) which supports Goal 1.1 (systemizing the innovation network) and Rule 10 (team training to overcome knowledge gaps). Rule 8 contains a list of criteria to structure the network 
and Rule 11 emphasizes work per process, which supports the involvement of all areas affected by the system (Goal 1.1.2)

The internalization of knowledge produced by the company (Rule 4) is part of a process to create a culture of organizational knowledge management (Goal 1.4). Rule 6 defines the criteria for project documentation, necessary for creating a database of learned lessons (Goal 1.4.1).

Rule 12 defines the need to establish scenarios before and after implementation to assess the impact of the system in the company (Goal 1.2.2). The definition of the network morphology (Rule 13) is required to establish a work plan that is consistent with the available resources (Goal 1.1.1). The systematization of the business process (Goal 1.3.3) requires the definition of a set of indicators (Rule 14) to evaluate the results. To align the project with the overall goals (Goal 1.2.1) the company's macro goals must be known (Rule 15).

The careful selection of a multidisciplinary team (Rule 2) helps to integrate IT and the business areas (Rule 16), which in turn enhances the company's use of internal knowledge (Goal 1.3.2). One way to bring the two teams together is through alignment meetings between the internal team members even before hiring the consultants (Rule 7).

Figure 5 shows the Business Rules Model.

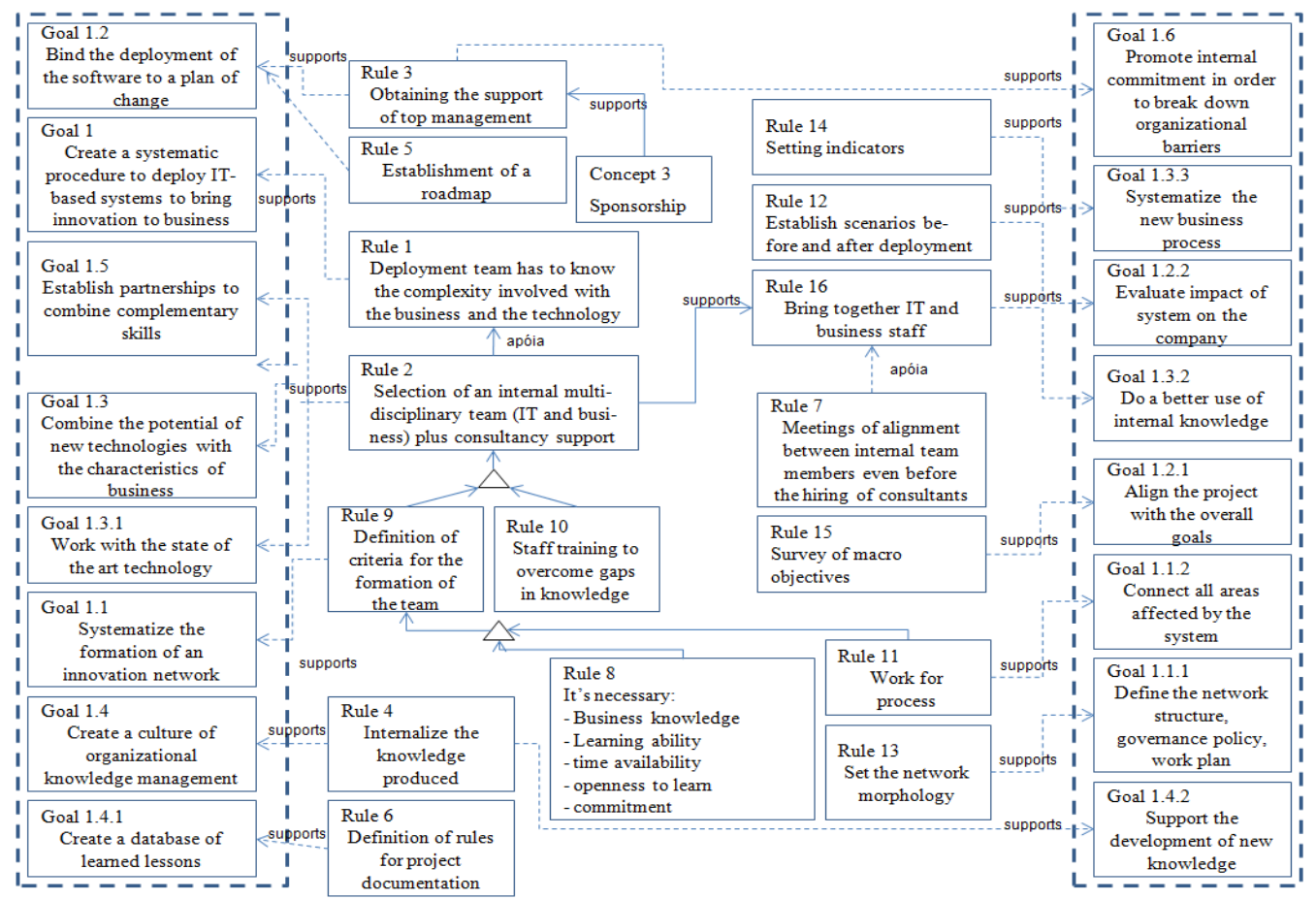

Figure 5. Business Rules Model f the research.

\subsection{Business processes model}

Within the scope of this research the work to implement Information Technology-based systems was linked to the life cycle of innovation networks and, as a consequence, the Business Process Model presented eight major processes. Process 1 (decision to innovate a business area by implementing a software) starts outside the scope of this research and its outputs are general guidelines such as time, budget available and desired macro features.

The first process addressed by this research is the configuration of the internal network that include IT and business areas (Case 2). The output of this process ensures that the 
company has the expertise to assess the demand imposed by their business. The first rule (Rule 1) defines the scope for selecting the agents of the network, while Rule 13 provides its morphological structure in terms of node, position, connection and flow. Rule 1 is performed by Role 2, defined in Actors and Resources Model as an implementation team.

Process 3 addresses the operation of the internal network, whose output is a premodeling that includes the software requirements from the business needs (Rule 17). The purchasing decision (Process 4 ) taken by senior management (Role 1) refers to the choice of software and consulting, and receives support in the information produced in Process 3.

Once software is purchased and the consulting firm is hired, the network undergoes a reconfiguration (Process 5). The output of this process is the system implementation multidisciplinary team, consisting of representatives from all areas involved and the consultants hired.

Process 6 (network operation) begins with the need to make a legated integration, that is, considering the current context (Rule 18), and continues to establishing before and after implementation scenarios. The output of this process is the implemented software with the added value to the business.

Process 7 addresses the dissolution of the network considering the management and the internalization of knowledge (Rule 4). The goal of this process is to ensure that the knowledge produced during the project time is not be lost with the withdrawal of the consultants and the dispersion of internal agents.

Process 8 starts from the concept of continuous improvement to predict future changes in the system implemented in line with the reference model. The output of this process is the company being prepared to easily respond to the market and gain competitive advantage.

Figure 6 shows the Business Processes Model.

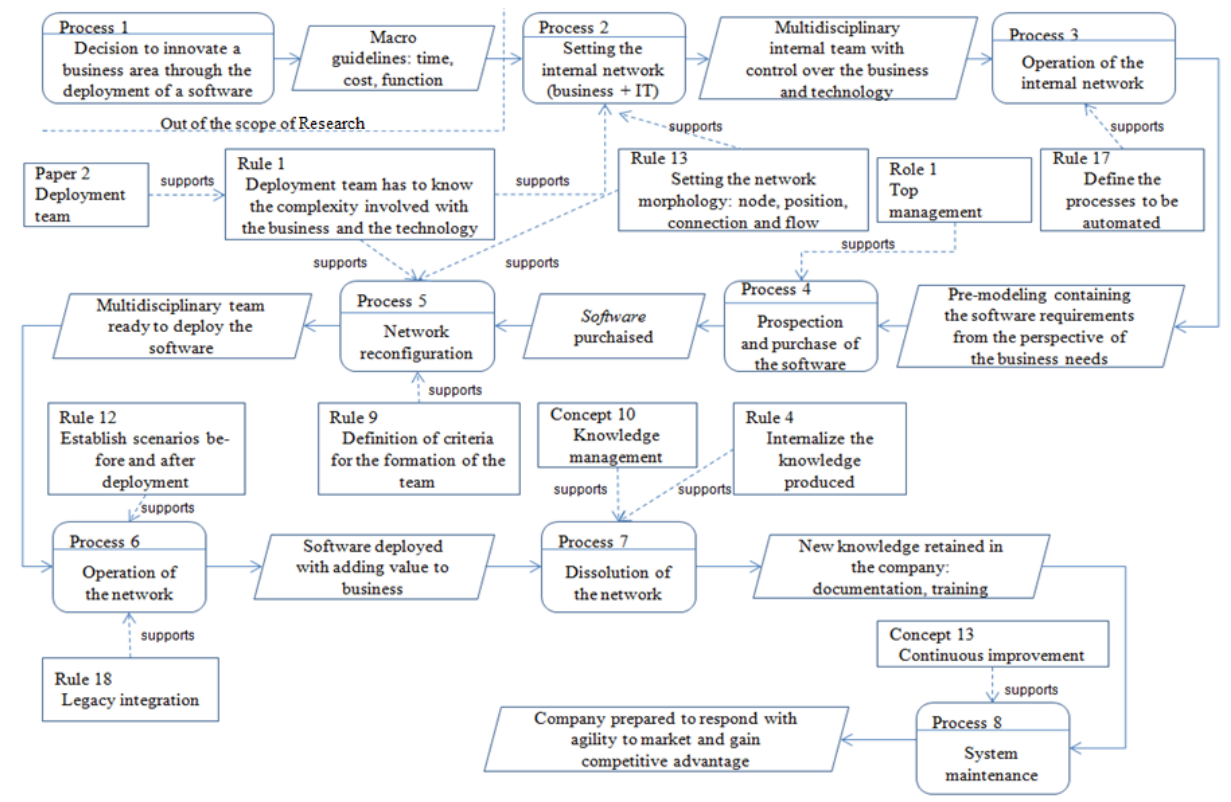

Figure 6. Business Processes Model of the research.

\subsection{Actors and resources model}

This model is contextualized to the Business Processes Model. The support from top management (Paper 1) is fundamental to the decision to innovate a business area by 
implementing a software (Case 1), both financially (Resource 3 ) as well as by the influence and power of persuasion with the employees, that is, the ability to sponsor the project (Concept 3 ). It is noteworthy that a norm defined by senior management is the need to respect the budget forecasted for the project (Rule 19).

The deployment team (Paper 2) is responsible for the preparation of the pre-models (Resource 1), the final models (Resource 7) and the roadmap for the implementation. The team is also responsible for the execution of Processes 2, 3, 5, 6 and 7 . Role 2 can be decomposed into several roles, business area coordinator (Paper 3), key users (Paper 5), IT coordinator (Paper 4) and consultants (Role 6). The coordinator of the business area and the key users provide support to the business (Resource 5). The coordinator of the IT department provides technical support (Resource 4) and infrastructure (Resource 6).

To satisfy Rule 4, which states that the knowledge produced should be internalized, we use the concept of knowledge management (Concept 10), which supports the dissolution process of the network (Case 7). The role of the manager of the innovation and continuous improvement (Paper 7 ) is to support Process 8 with the goal of making improvements in the system implemented.

Figure 7 shows the Actors and Resources Model.

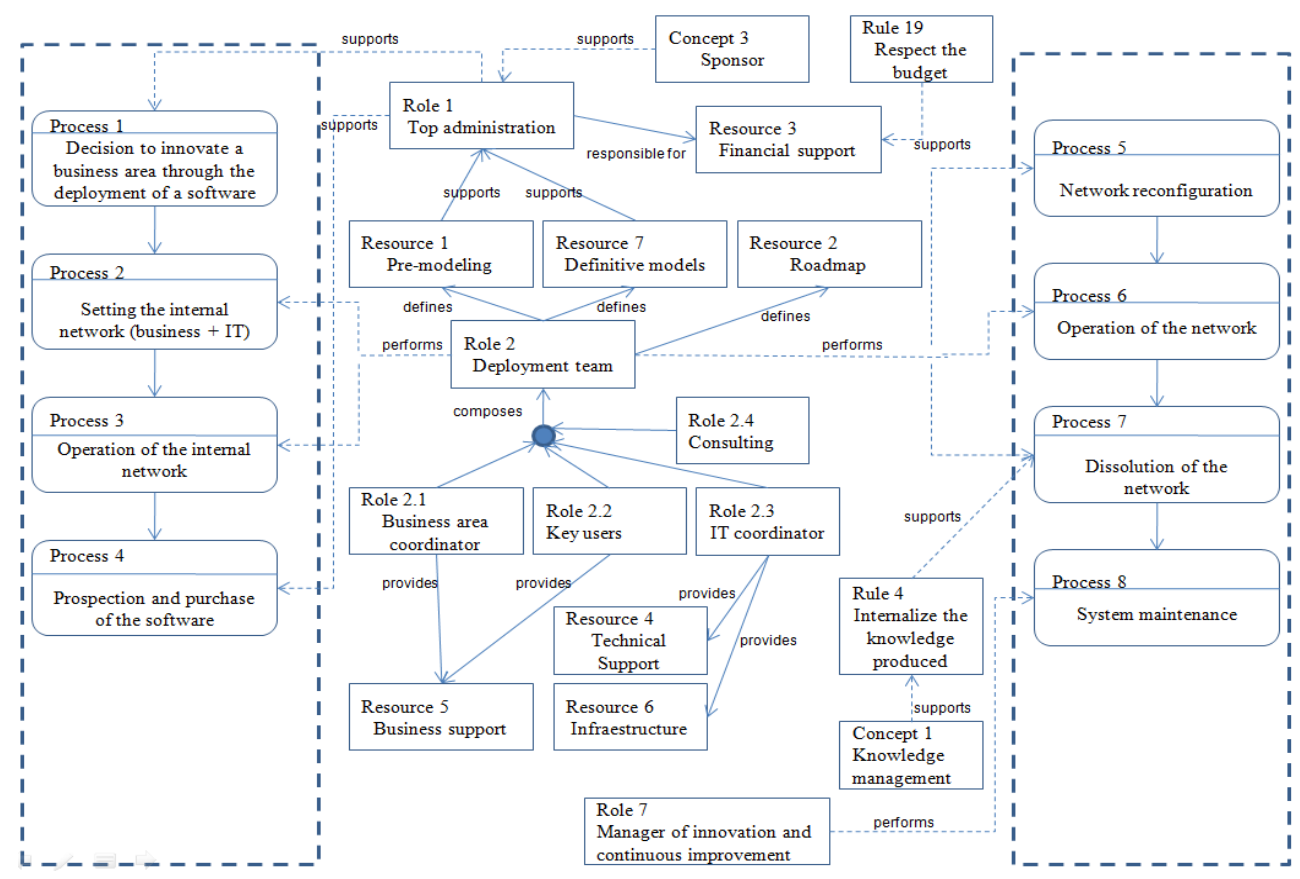

Figure 7. Actors and resources model.

\subsection{Concepts model}

The Concepts model is supported primarily by the innovation concept of the business (Concept 1) through the systematic implementation of IT-based systems (Goal 1). Every innovation causes a paradigm shift (Concept 2), which in turn requires support from a sponsor to help break down any resistance (Concept 3 ). Innovation also requires networking (Concept 4), which supports the role of the implementation staff (Paper 2). The network requires diversity of partners (Concept 7 ) and creating a relationship of trust and commitment between the parties (Concept 5). The diversification of partners supports the 
existence of the rule that establishes the need for the involvement of all areas affected by the system (Goal 1.1.2). The trust and commitment within the network require a clear, objective and transparent communication (Concept 6) so that people do not have unfounded fears and at the same time feel valued.

The innovation concept (Concept 1) supports the rule that defines the need for specifying a work script (Rule 5). Through it the deadlines, procedures and resources for the project activities will be associated. As the concept of innovation involves the aggregation of single values which are difficult to be reproduced by competitors (Concept 14), the achievement of this goal requires a close relationship between the project goals and the organization macro goals (Concept 8 ). Therefore, it is necessary to explore the internal and external knowledge (Concept 9 ) for a broad understanding of the scope of the project and its association with the macro business goals. Only a multidisciplinary team that relies on agents from all the internal areas most affected by the project and consultants hired from the market (Rule 2) can provide legitimacy to the relationship between project goals and the organizational goals (Goal 1.2.1). So that the team can explore internal knowledge, an efficient management of knowledge is required (Concept 10), so that it is not lost over time, which consists of the continuous training of personnel (Concept 11) and the standardized storage of information produced (Concept 12). The knowledge management enables the company to work on a platform of continuous improvement (Concept 13), while internalizing the knowledge produced over time (Rule 4). The organizational modeling (Concept 15) supports the concept of innovation in that it allows to establish before and after implementation scenarios (Rule 12). Following the main EKD guidelines, developing the models requires a legated integration that considers the current reality (Concept 21), assessment of project impacts (Concept 16) and detailed assessment of the risks involved (Concept 17).

Figure 8 shows the Concepts model.

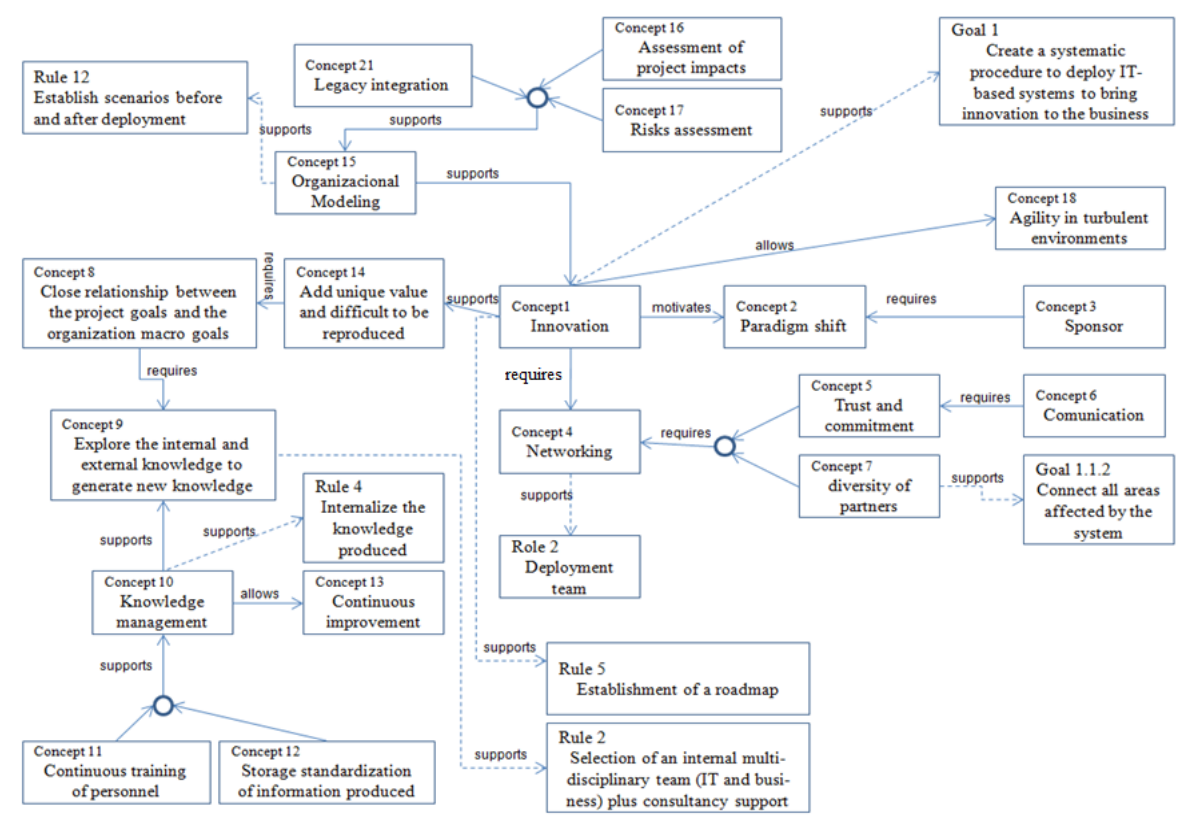

Figure 8. Concepts Model. 


\subsection{Discussion of the results}

Throughout the analysis units the accumulated lack of knowledge on the innovation concept and its requirements made difficult to establish clear goals that would bring innovative results to the organization, corroborating the works by Hoecht and Trott (2006) and Cohen and Levinthal (1990). The reference model addresses this gap by supporting Goal 1 (proposal to systematize the implementation of IT-based systems to bring innovation to the business) within the innovation concept (Concept 1) in the Concepts Model.

According to the Oslo Manual (Organização para Cooperação Econômica e Desenvolvimento, 2006) there is a positive relationship between the diversity of partners in a network and the innovation process, because the cooperative links are factors that transfer knowledge, resources and incentives, which are essential elements for innovation. However, merely alliance between the individuals was not able to guarantee good results. All the areas affected by the projects were not represented by the teams, nor was the criteria to integrate the networks defined, contradicting Kotilla \& Roni (2008), Soriano \& Urbano (2009), Abreu et al. (2009), Plisson et al. (2007) and Ermilova \& Afsarmanesh (2007), Yoshimura et al. (2005) and Abreu et al. (2009), to whom the commitment among the network members undergoes establishing clear requirements, skills and values for the integration and participation of the members. The proposed reference model covers this gap by combining a set of goals and rules with the systematization of a procedure to implement IT-based systems to bring innovation to the business (Goal 1.1) This enables the agents to form what Faems et al. (2005), Jesús Nieto \& Santamaría (2007), Palmberg (2006) call a diversified and renewed source of knowledge.

The involvement of the internal IT area was greater in the infrastructure than in the business processes. The distance between IT professionals and business specialists contradicts Andersson et al. (2008), Mohamed et al. (2006) and Wu et al. (2006), Hsu (2005) and Hallikas et al. (2008), which suggest that the complexity of new technologies and the business itself require an effective collaboration process among the agents specialized in the different areas involved. The reference model covers this gap by proposing rules to enable an approximation between the IT and business areas (Rule 16 and Rule 7) to improve the use of internal knowledge (Goal 1.3.2).

As a consequence of the lack of innovation concepts and networking, there was an improper transfer of responsibilities to the consultants. Andersson et al. (2008), Prajogo \& Ahmed (2006), Zain et al. (2005) and Sherehiy et al. (2007) suggest that the lack of articulation of qualified human resources is one of the factors considered harmful to the innovation capacity. The model proposed establishes the rules for the selection and training of a multidisciplinary team to work by means of processes (Rules 2, 8, 9, 11), in which responsibilities can be shared.

There is evidence of the low internalization of knowledge in the units of analysis due to the difficulty in coordination among the internal agents, transfer of responsibilities to the consultancies and lack of project documentation. The model bridges this gap by proposing the formation of an internal multidisciplinary team (Rule 2) which facilitates the approximation of IT with the business areas (Rule 16), and if necessary, training in order to overcome the agents' knowledge gaps (Rule 8). The model can also help to standardize the registration and access of information distributed throughout the enterprise in the form of an organizational knowledge databank (Goal 1.4). This mechanism supports the development of a culture of knowledge management.

The lack of adherence of the systems implemented in the company's businesses contradicts Barney (1991), Mohamed et al. (2006) and Ettlie et al. (2005), which suggest that the alignment between new technologies and the organization's goals is what generates 
change, which in turn is able to add value to the business. The reference model leads to this alignment naturally by setting up systemic goals supported by well-defined rules.

The reference model also helps to include all areas affected by the project and bring IT closer to the business areas, focusing more on the processes than on the hierarchical structure of the company and bringing two innovations, namely breaking down the departmental barriers and combining the complementary skills.

The flexibility provided by the reference model, represented in the syntax and semantics of EKD, enables foreseeing the likely impacts and consequences of a possible need for changes in their processes. In addition, the benefit provided by the databank of learned lessons, documented by the models, supports the decrease of a risk of making the same mistakes over time.

\section{Conclusion}

Research has shown that the intention to innovate is a necessary requirement, but is not enough to accomplish it. The units of analysis that formed the case study had the goal of innovation through IT, but have run into similar problems while conducting their projects. The evaluation of these issues in light of the literature review and the EKD methodology enabled proposing the reference model.

The proposed model answers the research question by providing guidelines for the company innovate through the resources provided by IT, allowing it to act proactively in face of the difficulties. The reference model also contributes to consolidating the knowledge produced by the innovation networks, addressing the life-cycle management of networks and the reconciling of the different views and interests within the enterprise (business area, technology and human resources) under the perspective of the EKD methodology.

The case study, as a research methodology, allowed to investigate which circumstances contributed to the formation of networks (life cycle), how the process of change was conducted from each project and what fate the knowledge produced had. The lack of concepts about innovation, the difficulties in the formation and operation of the networks and absence of policies to manage the knowledge produced were detected. Thus, the research brings criticism about the coordination of the implementation process of IT-based systems within companies, and as a contribution, it proposes a reference model to systematize the formation of innovation networks to support these implementations. The systematization goal is the use of a generic model to minimize the effects of a short-term outlook and to support the management of the change process. For this reason, it seeks to align the project with the overall goals of the organization, ensuring the integration of processes that are very relevant to the business, and establish a working script grounded on simulation scenarios and the accumulation of knowledge internalized by the projects over time.

The reference model is important to clarify the main elements based on goals, business rules, business process, actors and resources evolved to the IT-based systems implementation team.

The reference model has contributed to learning, understanding and comprehension of the topic, helping the development of knowledge about IT-systems implementation. It is useful formalization to guide the managers to the decision facing the possibility of restructuring the relationship among companies and to act collaboratively with its implementation partners.

The problems encountered while the projects were conducted were discussed with the coordinators of each unit of analysis, verifying the ability of the model to bridge such gaps. 
The evaluations of the coordinators were very positive in this regard. However, the presentation of these results to the company revealed the indifference of some individuals with regards to discussing situations of conflict, whose behavior is the outcome of the change-resistant culture.

For future work, there is a need to look for ways to build trust within the network, increasing the mutual commitment among the agents. The degree of innovation is another point to be explored, according to the suggestion of assessing the change in culture, in people and the behavior of the system as a whole.

\section{References}

Abreu, A., Macedo, P., \& Camarinha-Matos, L. M. (2009). Elements of a methodology to assess the alignment of core-values in collaborative networks. International Journal of Production Research, 47(17), 4907-4934. http://dx.doi.org/10.1080/00207540902847447.

Al-Ahmad, W., Al-Fagih, K., Khanfar, K., Alsamara, K., Abuleil, S., \& Abu-Salem, H. (2009). A Taxonomy of an It Project Failure: root Causes. International Management Review, 5(1)

Amara, N., \& Landry, R. (2005). Sources of information as determinants of novelty of innovation in manufacturing firms: evidence from the 1999 statistics Canada innovation survey. Technovation, 25(3), 245-259. http://dx.doi.org/10.1016/S0166-4972(03)00113-5.

Andersson, M., Lindgren, R., \& Henfridsson, O. (2008). Architectural knowledge in interorganizational IT innovation. The Journal of Strategic Information Systems, 17(1), 19-38. http://dx.doi.org/10.1016/j.jsis.2008.01.002.

Armoutis, N., Maropoulos, P. G., Matthews, P., \& Lomas, C. (2008). Establishing agile supply networks through competence profiling. International Journal of Computer Integrated Manufacturing, 21(2), 166-173. http://dx.doi.org/10.1080/09511920701607683.

Bagheri, S., Kusters, R. J., Trienekens, J. J. M., \& Grefen, P. W. P. J. (2019). A reference modelbased user requirements elicitation process: toward operational business-IT alignment in a cocreation value network. Information and Software Technology, 111, 72-85. http://dx.doi.org/10.1016/j.infsof.2019.03.012.

Barney, J. (1991). Firm resources and sustained competitive advantage. Journal of Management, 17(1), 99-120. http://dx.doi.org/10.1177/014920639101700108.

Bartel, A., Ichniowski, C., \& Shaw, K. (2007). How does information technology affect productivity? Plant-level comparisons of product innovation, process improvement, and worker skills. Quarterly Journal of Economics, 122(4), 1721-58.

Becker, W., \& Dietz, J. (2004). R\&D cooperation and innovation activities of firms - evidence for the German manufacturing industry. Research Policy, 33(2), 209-223. http://dx.doi.org/10.1016/j.respol.2003.07.003.

Bharadwaj, S., Bharadwaj, A., \& Bendoly, E. (2007). The Performance effects of complementarities between information systems, marketing, manufacturing, and supply chain processes. Information Systems Research, 18(4), 437-453. http://dx.doi.org/10.1287/isre.1070.0148.

Bubenko, J. A. Jr., Persson, A., \& Stirna, J. (2001). User guide of the knowledge management approach using enterprise knowledge patterns, deliverable D3, IST Programme project hypermedia and pattern based knowl-edge management for smart organisations, project no. IST-2000-28401. Sweden: Royal Institute of Technology.

Camarinha-Matos, L., \& Afsarmanesh, H. (2005). Collaborative networks: a new science discipline, Journal of Intelligent Manufacturing, 16, 439-452.

Camarinha-Matos, L., \& Afsarmanesh, H. (2008). On reference models for collaborative network organizations. Journal of Production Research, 46(7), 2453-2569.

http://dx.doi.org/10.1080/00207540701737666. 
Carvalho, H. L., \& Guerrini, F. M. (2017). Reference model for implementing ERP systems: an analytical innovation networks perspective. International Journal of Production Planning \& Control (Print), 28(4), 281-294. http://dx.doi.org/10.1080/09537287.2016.1273409.

Chen, J. S. J., \& Tsou, H. T. (2007). Information technology adoption for service innovation practices and competitive advantage: the case of financial firms. Information Research, 12(3), 314-324.

Chesbrough, H., \& Prencipe, A. (2008). Networks of innovation and modularity - a dynamic perspective. International Journal of Technology Management, 42(4), 414. http://dx.doi.org/10.1504/IJTM.2008.019383.

Cohen, W. M., \& Levinthal, D. A. (1990). Absorptive capacity: A new perspective on learning and innovation. Administrative Science Quarterly, 35(1), 128-152. http://dx.doi.org/10.2307/2393553.

Emden, Z., Calantone, R., \& Droge, C. (2006). Collaborating for new product development: Selecting the partner with maximum potential to create value. The Journal of Product Innovation Management, 23, 330-341.

Ermilova, E., \& Afsarmanesh, H. (2007). Modeling and management of profiles and competencies in VBEs. International Journal of Intelligent Manufacturing, 18(5), 561-586. http://dx.doi.org/10.1007/s10845-007-0066-0.

Ettlie, J. E., Perotti, V. C., Joseph, D. A., \& Cotteleer, M. J. (2005). Strategic predictors of successful enterprise system deployment. International Journal of Operations \& Production Management, 25(10), 953-972. http://dx.doi.org/10.1108/01443570510619473.

Faems, D., Looy, B. V., \& Debackere, K. (2005). Interorganizational Collaboration and Innovation: Toward a Portfolio Approach. The Journal of Innovation Management, 22(3), 238-250. http://dx.doi.org/10.1111/j.0737-6782.2005.00120.x.

Freel, M. S., \& Harrison, R. T. (2006). Innovation and cooperation in the small firm sector: evidence from 'Northern Britain. Regional Studies, 40(4), 289-305. http://dx.doi.org/10.1080/00343400600725095.

Grover, V., Teng, J., Segars, A.H., \& Fiedler, K. (1998). The influence of information technology diffusion and business process change on perceived productivity: The IS executive's perspective. Information \& Management, 34, 141-159.

Hallikas, J., Karkkainen, H., \& Lampela, H. (2009). Learning in networks: an exploration from innovation perspective. International Journal of Technology Management, 45(3/4), 229. http://dx.doi.org/10.1504/IJTM.2009.022650.

Hallikas, J., Varis, J., Sissonen, H., \& Virolainen, V. (2008). The evolution of the network structure in the ICT sector. International Journal of Production Economics, 115(2), 296-304. http://dx.doi.org/10.1016/j.ijpe.2007.11.014.

Hausman, A. (2005). Innovativeness among small businesses: theory and propositions for future research. Industrial Marketing Management, 34(8), 773-782. http://dx.doi.org/10.1016/j.indmarman.2004.12.009.

Higuera, R. P., \& Haimes, Y. Y. (1996). Software Risk Management (Technical Report, CMU/SEI96-TR-012, ESC-TR-96-012. Pittsburgh, Pennsylvania: Software Engineering Institute.

Hoecht, A., \& Trott, P. (2006). Innovation risks of the strategic outsourcing. Technovation, 26(5-6), 672-681. http://dx.doi.org/10.1016/j.technovation.2005.02.004.

Hsu, C. (2005). Formation of industrial innovation mechanisms through the research institute. Technovation, 25(11), 1317-1329. http://dx.doi.org/10.1016/j.technovation.2004.06.002.

Iyer, G. R., Laplaca, P. J., \& Sharma, A. (2006). Innovation and new product introductions in emerging markets - Strategic recommendations for the Indian market. Industrial Marketing Management, 35(3), 373-382. http://dx.doi.org/10.1016/j.indmarman.2005.02.007. 
Jesús Nieto, M., \& Santamaría, L. (2007). The importance of diverse collaborative networks for the novelty of product innovation. Technovation, 27(6-7), 367-377. http://dx.doi.org/10.1016/j.technovation.2006.10.001.

Katzy, B.R., \& Crowston, K. (2008). Competency rallying for technical innovation-The case of the Virtuelle Fabrik. Technovation, 28(10), 679-692.

Kirikova, M. (2000). Explanatory capability of enterprise models. Data \& Knowledge Engineering, 33(2), 119-136. http://dx.doi.org/10.1016/S0169-023X(99)00048-8.

Kotilla, M. R., \& Roni, P. (2008). Collaboration and trust in two organic food chains. British Food Journal, 110(4/5), 376-394. http://dx.doi.org/10.1108/00070700810868915.

Kwak, Y. H., \& Stoddard, J. (2004). Project risk management: lessons learned from software development environment. Technovation, 24(11), 915-920. http://dx.doi.org/10.1016/S01664972(03)00033-6.

Lee, A.H.I., Chen, H.H., \& Tong, Y. (2007). Developing new products in a network with efficiency and innovation. International Journal of Production Research, 46(17), 4687-4707.

Legris, P., Ingham, J., \& Collerette, P. (2003). Why do people use information technology? A critical review of the technology acceptance model. Information \& Management, 40(3), 191204. http://dx.doi.org/10.1016/S0378-7206(01)00143-4.

Mohamed, M., Stankosky, M., \& Murray, A. (2006). Knowledge management and information technology: can they work in perfect harmony? Journal of Knowledge Management, 10(3), 103-116. http://dx.doi.org/10.1108/13673270610670885.

Najafi-Tavani, S., Najafi-Tavani, Z., Naudé, P., Oghazi, P., \& Zeynaloo, E. (2018). How collaborative innovation networks affect new product performance: product innovation capability, process innovation capability, and absorptive capacity. Industrial Marketing Management, 73, 193-205. http://dx.doi.org/10.1016/j.indmarman.2018.02.009.

Nurcan, S., \& Rolland, C. (2003). A multi-method for defining the organizational change. Information and Software Technology, 45(2), 61-82. http://dx.doi.org/10.1016/S09505849(02)00162-3.

Organização para Cooperação Econômica e Desenvolvimento. (2006). Manual de Oslo. Proposta de diretrizes para coleta e interpretação de dados sobre inovação tecnológica. OECD, Finep.

Palmberg, C. (2006). The sources and success of innovations - Determinants of commercialisation and break-even times. Technovation, 26(11), 1253-1267. http://dx.doi.org/10.1016/j.technovation.2005.09.019.

Patrakosol, B., \& Olson, D. L. (2007). How interfirm collaboration benefits IT innovation. Information \& Management, 44(1), 53-62. http://dx.doi.org/10.1016/j.im.2006.10.003.

Plisson, J., Ljubic, P., Mozetic, I., \& Lavrac, N. An ontology for virtual organization breeding environments. IEE Transactions on Systems, Man, and Cybernetics - Part C: Applications and Reviews, 37(6), 1327-1341. 2007.

Prajogo, D. I., \& Ahmed, P. K. (2006). Relationships between innovation stimulus, innovation capacity, and innovation performance. $R$ \& D Management, 36(5), 499-515. http://dx.doi.org/10.1111/j.1467-9310.2006.00450.x.

Patrakosol, B., \& Olson, D.L. (2007). How interfirm collaboration benefits IT innovation. Information \& Management, 44, 53-62.

Rycroft, R. W., \& Kash, D. E. (2004). Self-organizing innovation networks - implications for globalization. Technovation, 24(3), 187-197. http://dx.doi.org/10.1016/S0166-4972(03)000920 .

Ryssel, R., Ritter, T., \& Gemünden, H.G. (2004). The impact of information technology deployment on trust, commitment and value creation in business relationships. Journal of Business \& Industrial Marketing, 19(3), 197-207. 
Sari, B., Sen, T., \& Kilic, S. E. (2007). Formation of dynamic virtual enterprises and enterprise networks. International Journal of Advanced Manufacturing Technology, 34(11-12), 12461262. http://dx.doi.org/10.1007/s00170-006-0688-y.

Sherehiy, B., Karwowski, W., \& Layer, J. K. (2007). A review of enterprise agility - concepts, frameworks, attributes. International Journal of Industrial Ergonomics, 37(5), 445-460. http://dx.doi.org/10.1016/j.ergon.2007.01.007.

Silva, A. L., \& Guerrini, F. M. (2018). Self-organized innovation networks from the perspective of complex systems. Journal of Organizational Change Management, 31(5), 968-983. http://dx.doi.org/10.1108/JOCM-10-2016-0210.

Soriano, D. R., \& Urbano, D. (2009). Overview of collaborative entrepreneurship: an integrated approach between business decisions and negotiations. Group Decision and Negotiation, 18(5), 419-430. http://dx.doi.org/10.1007/s10726-008-9134-x.

Swafford, P.M., Ghosh, S., \& Murthy, N. (2008). Achieving supply chain agility through IT integration and flexibility. International Journal of Production Economics, 116, 288-297.

Tsai, K. H. (2009). Collaborative networks and product innovation performance. Research Policy, 38(5), 765-778. http://dx.doi.org/10.1016/j.respol.2008.12.012.

Weichhart, G., Stary, C., \& Vernadat, F. (2018). Enterprise modelling for interoperable and knowledge-based enterprises. International Journal of Production Research, 56(8), 28182840. http://dx.doi.org/10.1080/00207543.2017.1406673.

Wu, F., Yeniyurt, S., Kim, D., \& Cavusgil, T. (2006). The impact of information technology on supply chain capabilities and firm performance: A resource-based view. Industrial Marketing Management, 35(4), 493-504. http://dx.doi.org/10.1016/j.indmarman.2005.05.003.

Yi, M. Y., Jackson, J. D., Park, J. S., \& Prosbst, J. C. (2006). Understanding information technology acceptance by individual professionals: toward an integrative view. Information \& Management, 43(3), 350-363. http://dx.doi.org/10.1016/j.im.2005.08.006.

Yin, R. K. (2005). Estudo de Caso - Planejamento e Métodos. Porto Alegre. The Bookman

Yoshimura, M., Izui, K., \& Kida, S. (2005). Decision Support System for Selecting Collaborative Product Development Partners. Concurrent Engineering, 13(1), 5-11. http://dx.doi.org/10.1177/1063293X05050910.

Zain, M., Rose, R. C., Abdullah, I., \& Masrom, M. (2005). The relationship between information technology acceptance and organizacional agility in Malaysia. Information \& Management, 42(6), 829-839. http://dx.doi.org/10.1016/j.im.2004.09.001.

Zeng, S. X., Xie, X. M., \& Tamc, C. M. (2010). Relationship between cooperation networks and innovation performance of SMEs. Technovation, 30(3), 181-194. http://dx.doi.org/10.1016/j.technovation.2009.08.003.

Zeraati, H., \& Rajabion, L. (2020). A model for examining the effect of knowledge sharing and new IT-based technologies on the success of the supply chain management systems. Kybernetes. 49(2), 229-251. https://doi.org/10.1108/K-06-2018-0280 